\title{
Duurzame onzekerheid en onenigheid
}

\section{Introductie}

We leven momenteel in een fase van de wereldgeschiedenis die gekenmerkt wordt door mondiale veranderingsprocessen - global change. Het gaat om een heel complex van samenhangende processen op economisch, politiek, cultureel, ideologisch en technologisch vlak, waarvan voorlopig niet duidelijk is hoe de uiteindelijke winst- en verliesrekening eruit zal zien. In ieder geval lijken deze processen hand in hand te gaan met enorme milieuproblemen: opwarming van de aarde, stijging van de zeespiegel, aantasting van de ozonlaag, verlies van biodiversiteit, versnippering van habitats, verspreiding van ziekten, luchtverontreiniging, chemische vervuiling, ontbossing, bodemdegradatie, verwoestijning, energietekorten et cetera. Al deze milieuproblemen hebben een grensoverschrijdend karakter en kunnen dan ook alleen maar via internationale samenwerking worden aangepakt. Bovendien zijn deze problemen onverbrekelijk met elkaar verbonden en kunnen derhalve niet met succes los van elkaar behandeld worden. ${ }^{1}$ Klimaatverandering bijvoorbeeld kan leiden tot een aantasting van de ozonlaag, tot verlies van biodiversiteit, verstoring van de globale waterhuishouding, verarming van de grond en verwoestijning enzovoort. Door het bestaan van positieve terugkoppelingsmechanismen tussen deze processen kunnen de destructieve effecten elkaar wederzijds versterken. Dit kan leiden tot serieuze bedreigingen van de productiviteit van de bodem en de oceanen, het voedselaanbod en de hoeveelheid en kwaliteit van het drinkwater en kan dus zijn weerslag hebben op de economie, op de voedselvoorziening en de volksgezondheid.

Vanwege hun grensoverschrijdende karakter en ook omdat ze zo innig met elkaar verweven zijn, vragen deze mondiale bedreigingen om een geïntegreerde en georkestreerde aanpak. Een meer duurzaam beheer van onze natuurlijke hulpbronnen vraagt met andere woorden om samenwerking - lokaal, nationaal, regionaal, globaal - tussen diverse partijen: overheden, bedrijfsleven, maatschappelijke organisaties. Maar die broodnodige samenwerking is allerminst vanzelfsprekend, veeleer uiterst problematisch, omdat we niet van doen hebben met één enkele wereldgemeenschap maar juist met een grote veelheid en verscheidenheid van groepen en gemeenschappen met verschillende wereldbeschouwingen die zelden met elkaar stroken en soms met elkaar botsen. Ziedaar de kernvraag van dit artikel: hoe zijn - ten behoeve van een duurzaam beheer van natuurlijke hulpbronnen - communicatie, coördinatie en coöperatie mogelijk tussen groepen en gemeenschappen met uiteenlopende ethische visies en morele vocabulaires? Hoe kan de spanning tussen diversiteit en duurzaamheid worden opgelost? 
gen. En in de tweede plaats zijn er dan veelal sterk conflicterende belangen en waarden in het geding. Onder deze omstandigheden schieten de onderzoeksstrategieen van de 'normale' wetenschap tekort en ontstaat er behoefte aan wat Silvio Funtowicz en Jerome Ravetz 'postnormale' wetenschap noemen. Overigens zijn die twee variabelen - onzekerheid en onenigheid - niet geheel onafhankelijk van elkaar: hoe groter de onenigheid, hoe meer de onzekerheid alle nadruk krijgt, en omgekeerd.

De notie van 'normale' wetenschap ontlenen Funtowicz en Ravetz aan de wetenschapsfilosoof en wetenschapshistoricus Thomas Kuhn. Deze onderscheidt twee soorten wetenschap: 'normale' en 'revolutionaire' wetenschap. Normale wetenschap is altijd gebonden aan een paradigma. Daaronder verstaat Kuhn zoiets als een wereldbeschouwing die vastlegt uit welke fundamentele entiteiten het universum bestaat en welke relaties daartussen bestaan. Onder normale omstandigheden bestaat er onder wetenschappers uit een discipline overeenstemming over de manier waarop de empirische werkelijkheid beschouwd en benaderd moet worden, en ook over de vraag welke problemen de moeite waard zijn om onderzocht te worden, aan welke standaarden oplossingen moeten voldoen, hoe waarnemingen verricht moeten worden, wat een acceptabele verklaring is enzovoort.

In de normale wetenschap wordt een paradigma min of meer kritiekloos omhelsd. De centrale filosofische en theoretische uitgangspunten en vooronderstellingen worden niet voortdurend ter discussie gesteld, maar als vanzelfsprekend aanvaard. Dat is ook nodig om in de wetenschap vooruitgang te boeken en de groei van kennis te bevorderen. Onderzoekers staan voor de opgave om een steeds groter deel van de werkelijkheid waarop het paradigma betrekking heeft, in kaart te brengen en te verklaren. Kuhn vergelijkt deze activiteit ook wel met het oplossen van een legpuzzel. Het paradigma vormt als het ware de plaat waarop de contouren van die immense kennislegpuzzel zijn aangegeven. De taak van de wetenschappelijke groep is het steeds verder in elkaar zetten van de puzzel, daarbij geleid door de plaat. Het is niet zinvol om de plaat zelf ter discussie te stellen, dit zou het puzzelen geheel ondermijnen.

Welnu, het 'puzzeloplossend' vermogen van de normale wetenschap is volgens Funtowicz en Ravetz niet langer toereikend wanneer 'the facts are uncertain, values in dispute, stakes high and decisions urgent' - zoals hun favoriete formule luidt. In dat geval moet worden overgeschakeld op 'postnormale' wetenschap. Het belangrijkste kenmerk van dit type wetenschap is de gestage uitbreiding van de wetenschappelijke gemeenschap (de peer community) met experts van de meest diverse pluimage, maar ook met leken die bij de problematiek betrokken zijn of erdoor geraakt worden. Deze uitbreiding van het aantal stakeholders met hun diverse en vaak divergerende opvattingen heeft volgens Funtowicz en Ravetz ingrijpende gevolgen voor zowel de wetenschap als de samenleving. 'Met wederzijds respect tussen de verschillende perspectieven en kennisvormen, bestaat er een mogelijkheid voor de ontwikkeling van een authentiek en effectief democratisch element in het leven van de wetenschap.'3 Met de opkomst van postnormale wetenschap gaat de wetenschappelijke praktijk meer gelijkenis vertonen 'met het functioneren van een democratische maatschappij, die 
gekenmerkt wordt door uitgebreide participatie en tolerantie van diversiteit'.4 Kortom: 'Postnormale wetenschap kan de weg wijzen naar de democratisering van de wetenschap.' 5

De opvattingen van Funtowicz en Ravetz over normale en postnormale wetenschap vertonen een treffende gelijkenis met die van Helga Nowotny, Peter Scott en Michael Gibbons over twee soorten wetenschap die zij met de termen 'modus I' en 'modus 2' benoemen. Modus I wetenschap beantwoordt aan de klassieke visie van de 'zuivere', fundamentele, disciplinair georganiseerde en autonome, los van de samenleving staande wetenschap. Modus 2 wetenschap is daarentegen sterk toepassingsgericht, transdisciplinair en innig verweven met de samenleving.

Het huidige onderzoek vindt volgens Nowotny cum suis in toenemende mate plaats in een 'context van toepassing', waardoor de problemen van meet af aan geformuleerd worden in samenspraak met een groot aantal verschillende actoren met elk hun eigen perspectieven. Hierdoor wordt een grote heterogeniteit van vaardigheden en deskundigheden bij het oplossen van de problemen in kwestie betrokken. Modus 2 wetenschap is dan ook transdisciplinair; ze overschrijdt niet alleen de grenzen tussen disciplines, maar ook die tussen wetenschap en samenleving - het is moeilijk te bepalen waar de wetenschap eindigt en de maatschappij begint. In modus 2 zijn wetenschap en samenleving in een proces van co-evolutie op elkaar betrokken. Pas wanneer er sprake is van een geslaagde communicatie over en weer tussen wetenschap en samenleving ontstaat niet alleen betrouwbare maar bovendien 'sociaal robuuste' kennis.

Wanneer we Funtowicz, Ravetz, Nowotny en vele anderen mogen geloven, en daar is veel voor te zeggen, dan biedt de huidige wetenschap niet langer een oplossing voor het conflict tussen diversiteit en duurzaamheid. Tegenwoordig staat de wetenschap niet meer buiten of boven de maatschappij en kan dus ook niet meer gedacht worden als een onpartijdige instantie die objectieve maatstaven en universele richtlijnen voor toekomstig maatschappelijk handelen kan verschaffen. Naarmate de grenzen tussen wetenschap en samenleving meer en meer vervagen, dringen bestaande maatschappelijke tegenstellingen en conflicten steeds dieper door tot het hart van de wetenschap zelf.

\section{De zaden van verderf}

Op dit punt schetsen met name Funtowicz en Ravetz echter nog een veel te rooskleurig beeld. Zoals uit de hierboven aangehaalde passages uit hun klassieke artikel bleek, vergelijken zij postnormale wetenschap met een democratische maatschappij die gekenmerkt wordt door uitgebreide participatie en tolerantie van diversiteit. Aan het slot van dit artikel laten zij echter de volgende waarschuwing horen:

'Zoals bij elke ingrijpende overgang, bevat het heden zowel zaden van verderf als van vernieuwing. Sommige participanten in de strijd om het milieu zien wetenschappers slechts als huurlingen, die de data dienen te leveren die "wij" nodig hebben en die 
akkoord gaan met het achterhouden van de rest. Anderen houden zich doof voor enig argument of bewijs dat hun vooringenomen zaak zwakker maakt. Zijn zulke participanten legitieme leden van de uitgebreide wetenschappelijke gemeenschap? Zelfs de traditionele wetenschap heeft dergelijke types altijd opgenomen, maar er was wel sprake van een impliciete ethische plicht tot integriteit waarmee de gemeenschap in haar geheel de kwaliteit van haar werk veilig stelde' (754).

Hoe terecht deze waarschuwing is, blijkt bij een nadere analyse van de huidige klimaatwetenschappen, volgens Funtowicz en Ravetz één van de belangrijkste voorbeelden van postnormale wetenschappen. Hier hebben we te kampen met grote onzekerheden. Met het globale klimaat zijn geen experimenten mogelijk en we moeten het voornamelijk hebben van computersimulaties met een problematische voorspellende waarde. Het globale klimaatsysteem is een zeer complex, niet-lineair systeem met veel feedbackloops.

Die grote onzekerheid gaat gepaard met grote onenigheid. Het klimaatdebat zoals dat vooral in Amerika, maar momenteel ook in Nederland, wordt gevoerd, wordt namelijk sterk gedomineerd door de onoverbrugbaar lijkende ideologische tegenstellingen tussen conventionele (mainstream) klimaatwetenschappers enerzijds en klimaatsceptici of contrarians anderzijds. Samen met milieuactivisten vestigen conventionele klimaatwetenschappers de aandacht op het feit dat de klimaatsceptici slechts een kleine minderheid vormen, een feit dat door de sceptici wordt aangevochten.

Bovendien hameren ze er telkens weer op dat de sceptici gesponsord worden door conservatieve denktanks, zoals de Heritage Foundation, het Cato Institute en het Marshall Institute, die alle een nationalistische en libertaire koers voorstaan en zich evenzeer verzetten tegen internationaal bindende verdragen als tegen overheidsbemoeienis. Door een veelheid van activiteiten, zoals het bestoken van de media met een niet aflatende stroom persberichten, het organiseren van beleidsdebatten en het sponsoren van persconferenties voor beleidsmakers, verschaffen deze conservatieve denktanks een podium aan de klimaatsceptici. Behalve organisatorische steun ontvangen de klimaatsceptici ook financiële steun, niet alleen van de conservatieve denktanks, maar ook van de olie- en steenkoolindustrie - zoals de conventionele klimaatwetenschappers en de milieuactivisten niet moe worden te onderstrepen. ${ }^{6}$

Maar het verwijt van belangenverstrengeling is een tweesnijdend zwaard, omdat de sceptici of contrarians op hun beurt zullen wijzen op de economische en politieke belangen die in het kamp van de 'broeikasindustrie' of de 'broeikasmaffia' een rol spelen. Op dit punt is vooral stevig getamboereerd door hardcore scepticus Sonja BoehmerChristiansen, editor van Energy and environment, het lijfblad der sceptici. Zij claimt dat het gezaghebbende Intergovernmental Panel on Climate Change (IPCC) vanwege de eenzijdige samenstelling bevooroordeeld zou zijn. Het IPCC bestaat voornamelijk uit klimatologen en richt zich in het bijzonder op de resultaten van klimaatmodellen. Astronomen (in het bijzonder zij die het gedrag van de zon bestuderen), geologen, oceanologen, biologen en paleontologen, die sceptisch staan tegenover de hypothese dat de klimaatverandering door de mens veroorzaakt is, zouden van het IPCC uitgesloten zijn. 
lijke kring wisten te ontketenen. Alleen de tijdspanne waarin een en ander zich voltrekt, zou zeer sterk gecomprimeerd zijn: wat in werkelijkheid vele jaren zou duren, gebeurt in de film in een etmaal. Er mag dan een kern van waarheid in de film zitten, maar die is wel - zoals iemand het ooit heeft uitgedrukt - volgepompt met steroïden en onderworpen aan cosmetische chirurgie.

De film wil het grote publiek wakker schudden en het klimaat weer hoog op de politieke agenda plaatsen. Regisseur Emmerich heeft ook in interviews gezegd verbijsterd te zijn over de weigering van Bush om het Kyoto Protocol te ratificeren. De politieke boodschap van de film blijkt al meteen uit de tweede scène. Op een VN-klimaatconferentie in een met sneeuw bedekt New Delhi maant Jack Hall zijn gehoor tot snel ingrijpen om te voorkomen dat onze kinderen en kleinkinderen de prijs moeten betalen. 'En wie gaat het Kyoto-akkoord betalen?', vraagt Jacks tegenspeler, de Amerikaanse vicepresident, op hoge toon. 'Dat kost de wereld honderden miljarden.' De professor moet zich volgens deze Dick Cheney look-alike realiseren dat de economie even kwetsbaar is als het milieu voordat hij sensationele uitspraken doet over een dreigende ijstijd. Maar aan het eind van de film is de vicepresident tot inkeer gekomen. 'De afgelopen weken hebben ons doen beseffen hoe klein we zijn tegenover de verwoestende kracht van de natuur. We dachten dat we natuurlijke hulpbronnen konden blijven gebruiken zonder gevolgen. We hadden het mis.'

Voormalig vicepresident Al Gore, een groot voorstander van Kyoto, heeft de film aangegrepen om de regering-Bush de les te lezen. Ondanks het discutabele wetenschappelijke gehalte prijst Al Gore de film toch aan omdat hij laat zien dat het broeikaseffect een reëel probleem is. Wie dat ontkent, is volgens Al Gore nog veel 'fictiever' bezig dan de makers van de film.7 Dat is ook de reactie van het overgrote deel van de milieubeweging. Het gebrek aan wetenschappelijke geloofwaardigheid heeft de milieubeweging er niet van weerhouden de film aan te grijpen voor het beginnen van een nieuwe bewustwordingscampagne om het gevaar van opwarming van de aarde weer eens onder de aandacht van het grote publiek te brengen.

\section{Groen terrorisme}

Zoals te verwachten viel, hebben conservatieve groepen op hun beurt het fictieve karakter van de film aangegrepen om de pleitbezorgers van een stringent klimaatbeleid in diskrediet te brengen en hun boodschap als pure propaganda af te doen. $\mathrm{Zij}$ hebben ongetwijfeld hun hart opgehaald aan State offear, de ruim zeshonderd pagina's tellende 'technopolitieke thriller' waarmee Michael Crichton afgelopen december, uitgerekend aan de vooravond van de tiende VN-klimaatconferentie in Buenos Aires, het publiek verraste. Deze roman, die leest als een rabiaat rechts antwoord op The day after tomorrow, werd dan ook als 'kersttip' aanbevolen in de elektronische nieuwsbrief van de conservatieve Groene Rekenkamer. Milieuactivisten worden in deze roman, met een eerste druk van maar liefst 1,7 miljoen exemplaren, neergezet als vertegenwoordigers van een geldverslindende broeikasindustrie. Grote boosdoener is Nick 
Drake, president-directeur van het National Environmental Resource Fund, een milieuNGO. Om de stroom van donaties op peil te houden, proberen Drake en zijn kompanen het publiek in een permanente staat van angst te brengen waarbij geen enkel middel, hoe gewelddadig ook, geschuwd wordt: met geavanceerde technologieën proberen ze op Antarctica een enorme ijsschots los te wrikken, in Arizona een overstroming te veroorzaken en in de Grote Oceaan een heuse tsunami op te wekken.

Niet de uitstoot van $\mathrm{CO}_{2}$ en de klimaatverandering vormen in dit boek de grote bedreiging, maar de milieuactivisten zelf, die de mythe van de mondiale opwarming met veel 'natuurgeweld' leven proberen in te blazen. Zij worden afgeschilderd als meedogenloze terroristen die zelfs niet voor een massaslachting terugdeinzen om de mensheid te overtuigen van een non-existent gevaar om zo politieke macht en vooral veel geld te verwerven. In zijn bespreking van de roman heeft Chris Mooney het dan ook niet ten onrechte over 'pure porno voor de ontkenners van mondiale opwarming'. Hij spreekt van een 'perverse omkering' en trekt op dit punt een instructieve vergelijking met Disclosure, de roman waarin Crichton de kwestie van seksuele intimidatie op het werk aan de orde stelt via een geval waarin een vrouw een man lastigvalt.

De film en de roman maken duidelijk hoezeer het klimaatdebat in Amerika, maar ook daarbuiten, gepolitiseerd en gepolariseerd is. Hierbij lijkt het grote publiek aan het kortste eind te trekken omdat het niet langer weet wie het kan geloven en op wie het kan vertrouwen. Die situatie wordt nog verder verscherpt door de norm van 'evenwichtige berichtgeving' die door de media gehanteerd wordt, waarbij objectiviteit gelijkgesteld wordt aan het presenteren van de 'beide kanten van het verhaal'. De berichtgeving over controversiële onderwerpen verloopt volgens een 'pro en contra'model waarbij de meest extreme visies tegenover elkaar geplaatst worden en waarbij de journalist concludeert dat de kwestie onbeslist is. Als gevolg hiervan krijgen de sceptici in de media inmiddels evenveel aandacht als de meest gerenommeerde experts.

Het is duidelijk dat de wetenschap in het klimaatdebat, maar ook in andere maatschappelijke controverses, niet langer in staat is een oplossing te bieden voor het probleem van de spanning tussen diversiteit en duurzaamheid. In plaats van eenheid en eensgezindheid te bevorderen, is zij onder postnormale condities zelf midden in het maatschappelijke strijdperk beland en is zij haar autonome, onpartijdige of bovenpartijdige status voorgoed kwijtgeraakt. ${ }^{8}$ Dat roept opnieuw de vraag op hoe de spanning tussen diversiteit en duurzaamheid dan wel opgelost zou kunnen worden.

\section{De ene wereldgemeenschap en de verschuivingen in governance}

Krisis 2007 I 2 Een ander veelgehoord antwoord op deze vraag luidt: door te streven naar één wereldgemeenschap zonder grenzen. Volgens de bekende filosoof Peter Singer lijkt een gemeenschappelijke aanpak van mondiale problemen slechts een reële kans van slagen te hebben wanneer er een einde komt aan het anarchistische karakter van de wereldpolitiek, een karakter dat inherent is aan het systeem van soevereine staten dat 
zich sinds de Vrede van Westfalen in 1648 geleidelijk over de hele wereld heeft verspreid. In een tijdperk van globalisering moeten we volgens Singer korte metten maken met de idee van staatssoevereiniteit, moeten we voorbij de natiestaat denken en het besef ontwikkelen dat we met elkaar één enkele grote gemeenschap vormen. Vandaar zijn pleidooi voor een ethiek zonder grenzen - een echte 'één-wereldethiek' 9

Hoe sympathiek Singers pleidooi ook mag klinken, en hoezeer hij ook gelijk mag hebben met zijn relativering van de idee van staatssoevereiniteit, het post-Westfaalse tijdperk zal hoogstwaarschijnlijk niet in het teken staan van de opkomst en vestiging van één grote wereldgemeenschap zonder grenzen. ${ }^{10}$

Het proces van globalisering waar Singer in positieve zin naar verwijst, gaat namelijk in het gros der staten hand in hand met een proces van decentralisering en fragmentarisering van staatsmacht. De inperking van de staatsmacht 'van bovenaf gaat met andere woorden samen met een inperking 'van onderop'. Tussen lokale en globale organisaties en instellingen ontwikkelen zich bovendien steeds meer netwerken buiten de natiestaat om - een trend die Roland Robertson (1995) als 'glokalisering' heeft aangeduid.

Maar daarmee is het beeld verre van compleet. Want de politiek heeft zich niet alleen in bovenwaartse en benedenwaartse richting verplaatst maar eveneens zijdelings, deels naar de markt en deels naar de maatschappij (de civil society). Er is dus sprake van een tweedimensionale verschuiving in bestuurspraktijken en beleidsprocessen: een verticale verschuiving naar meer globale en meer lokale niveaus en een horizontale verschuiving naar markt en maatschappij. ${ }^{11}$

Zoals Onora O’Neill (2004) nog onlangs heeft opgemerkt, is er binnen de ethiek en politieke filosofie in het algemeen te weinig aandacht voor de rol van marktpartijen en maatschappelijke organisaties. Zij drijft niet alleen de spot met het vermeende realisme van etatistisch georiënteerde theoretici, maar verzet zich eveneens tegen het 'abstracte kosmopolitisme' van mensen als Singer, juist vanwege hun veronachtzaming van niet-statelijke actoren zoals non-gouvernementele organisaties (NGO's) en transnationale corporaties (TNC's).

Een van de belangrijkste gevolgen van de verplaatsing van de politiek langs horizontale en verticale assen is de enorme uitbreiding van het aantal beleidsactoren (multi-actor governance) en bestuurslagen (multi-level governance), met alle coördinatie- en communicatieproblemen van dien. Tegelijkertijd groeit de noodzaak om - ondanks deze heterogeniteit van stakeholders en het hieruit voortvloeiende pluralisme van belangen en waarden - tot een gezamenlijke strategie voor duurzaam beheer van natuurlijke hulpbronnen te komen. Ziedaar - opnieuw - het grote probleem waar wij voor staan: de spanning tussen diversiteit en duurzaamheid. Enerzijds is er een grote verscheidenheid van personen en partijen die bij beheer betrokken zijn, anderzijds is er de alom gevoelde noodzaak tot een geïntegreerde aanpak en een nauwe samenwerking van alle stakeholders met hun uiteenlopende levensbeschouwingen en wereldvisies. 


\section{Een nieuw wervend totaliteitsbesef?}

Vooral milieufilosofen en milieuactivisten vertonen de hardnekkige neiging om deze spanning op te lossen via het ontwerpen van een nieuwe metafysica of zelfs een nieuwe mythologie, die dan de eenheidsstichtende kracht zou bezitten die nodig is om aan de milieucrisis het hoofd te beiden. De meeste milieufilosofen en -activisten volgen Martin Heidegger in zijn kritiek op het antropocentrisme van de westerse metafysica. Wanneer de mens zich tot maat aller dingen opwerpt, verschijnt de natuur, met inbegrip van de menselijke natuur, nog slechts als 'materiaal', waarover hij naar eigen inzicht en goeddunken kan beschikken. Om te voorkomen dat deze crisis in een catastrofe eindigt, moeten we ons volgens de milieufilosofen van het antropocentrisme afwenden en tot het ecocentrisme bekeren: we mogen de dingen niet meer benaderen onder het aspect van hun bruikbaarheid en beschikbaarheid voor onze onverzadigbare wil tot macht, maar dienen juist een houding van behoedzaamheid en bezonnenheid aan te nemen. De mens moet leren zich eerder als hoeder of herder dan als heerser van de natuur te gedragen. De natuur mag niet langer uitsluitend op haar instrumentele betekenis voor onze zelfhandhaving worden beoordeeld, maar we moeten in plaats daarvan haar intrinsieke waarde erkennen en haar dus omwille van zichzelf leren respecteren.

De metafysische ziekte van de uitsluitend op beheersing en overheersing gerichte moderniteit valt slechts te bestrijden door een andere metafysica of een ander wereldbeeld te ontwerpen, doorgaans geschoeid op holistische leest en voorzien van een ecologisch keurmerk, onder het motto dat het geheel groter is dan de som der delen en dat alles met alles samenhangt.

Op dat punt kent de Nederlandse milieufilosoof Wim Zweers de minste schroom. Wat we volgens Zweers nodig hebben is een nieuw 'wervend' totaliteitsbesef, namelijk het bewustzijn dat er maar één orde is die alles omvat. We moeten een stuk van onze autonomie opgeven en leren ons te voegen naar en ons te 'laten gezeggen' door het grotere geheel, waarvan we slechts een onaanzienlijk deel uitmaken.

\section{De postmoderne conditie en het einde van de grote verhalen}

De poging om de spanning tussen diversiteit en duurzaamheid op te lossen door een nieuw eenheidsstichtend totaliteitsbesef is een doodlopende weg. Na lang aarzelen heeft de moderne filosofie deze weg van veelheid naar eenheid dan ook verlaten en is de tegenovergestelde weg ingeslagen: de weg van eenheid naar veelheid - naar differentie, decentrering, disseminatie, dissensus en discontinuïteit, om de voornaamste termen te noemen die daarvoor momenteel circuleren.

Het culminatiepunt van de weg van eenheid naar veelheid wordt gevormd door het werk van Jean-François Lyotard, die met veel tamtam het einde van de grote verhalen (méta-écrits) heeft verkondigd. Het wantrouwen van veel hedendaagse filosofen in grote verhalen is maar al te begrijpelijk. Dergelijke verhalen bezitten onvermijde- 
lijk een etnocentrisch karakter omdat ze bepaalde tijd- en plaatsgebonden preoccupaties weerspiegelen en de complexe werkelijkheid perspectivisch vertekenen. Zoals de recente geschiedenis laat zien, vertonen dergelijke geborneerde metaverhalen bovendien, juist vanwege hun totaliteitsaanspraken, terroristische trekken - zij verdringen of vernietigen alles wat niet in hun kraam past. Dat gevaar ligt natuurlijk ook op de loer bij alle ecologisch geïnspireerde toekomstbeelden ('groene utopieën') die onder milieufilosofen en milieuactivisten nog steeds populariteit genieten.

De postmodernistische kritiek op de grote verhalen is dus duidelijk normatief gekleurd. Maar ook vanuit een meer descriptief gezichtspunt lijken grote verhalen hun langste tijd gehad te hebben. Globalisering blijkt namelijk een proces waarin culturele homogenisering ('McDonaldisering') hand in hand gaat met culturele heterogenisering en fragmentering. Globalisering leidt tot een groeiend zelfbewustzijn bij veel inheemse volkeren en tot een 'herontdekking' en revitalisering van traditionele culturen en praktijken. Het wegvallen van geografische afstanden brengt uiteenlopende wereldbeschouwingen en leefstijlen direct met elkaar in contact. Hierdoor neemt de kans op stereotyperingen en conflicten toe, maar groeit eveneens de mogelijkheid tot wat de antropoloog Ulf Hannerz als 'creolisering' heeft aangeduid: het ontstaan van nieuwe culturele mengvormen. Ten slotte kan nog gewezen worden op het ontstaan van nieuwe transnationale gemeenschappen, die niet door een gezamenlijke oorsprong of door geografische nabijheid gekenmerkt worden, maar door een gemeenschappelijk belang of beroep, of door sociale en culturele overeenkomsten.

Hoewel het verlangen naar nieuwe grote eenheidstichtende verhalen maar al te begrijpelijk is in het licht van de mondiale milieuproblemen die om een integrale, gezamenlijke aanpak vragen, kan men dit verlangen dus maar beter weerstaan. We kunnen de zoektocht naar eenheidstichtende metaverhalen maar beter voorgoed staken en in plaats daarvan de veelheid en verscheidenheid van vertogen en vocabulaires, van wereldbeschouwingen en onderliggende waarden als factum brutum aanvaarden, en accepteren dat conflicten de regel zijn en dat consensus en compromissen de uitzondering vormen die deze regel bevestigt.

De drie voornaamste oplossingen voor de spanning tussen diversiteit en duurzaamheid komen allemaal neer op het indammen van de diversiteit, op het zoeken naar een nieuwe eenheid in de veelheid en verscheidenheid op sociaal, politiek en cultureel terrein. En alle drie ontpoppen ze zich als schijnoplossingen: het streven naar één wereldgemeenschap zonder grenzen is even onrealistisch als het streven naar één metafysische of mythologische wereldbeschouwing of het aanroepen van dé wetenschap als de enige echte arbiter waarnaar alle partijen zich nolens volens zullen moeten voegen. ${ }^{12}$

Wanneer we echter afscheid nemen van pogingen de bestaande diversiteit te 'vereenvoudigen' en wanneer we het pluralisme volmondig erkennen, dan wordt de vraag naar de mogelijkheidsvoorwaarden van samenwerking in het kader van een duurzaam beheer van natuurlijke hulpbronnen des te klemmender. Mijn antwoord op deze vraag luidt: we moeten investeren in grenswerk, dat wil zeggen in het stimuleren en faciliteren van communicatie, conflictmanagement en consensusvorming over de 
grenzen tussen groepen en gemeenschappen heen. Daarover gaat het tweede deel van dit artikel.

\section{Werken aan de grens}

In de deel zal ik ingaan op drie pragmatische methoden van grenswerk: het doorbreken van een polariserend zwart-wit denken door 'gradualisering', het herformuleren van problemen onder het motto van de pragmatist Anthony Weston Toward better problems, en het stimuleren van samenwerking tussen heterogene partijen door de creatie van zogenaamde 'grensobjecten'. ${ }^{13}$

\section{'Gradualisering' en de morele paniek rondom grote grazers}

Een van de struikelblokken voor grenswerk is het beginsel van non-contradictie dat reeds door Aristoteles geformuleerd werd. Het luidt: een bewering is waar of onwaar, een derde mogelijkheid bestaat niet: tertium non datur! Deze 'wet van de uitgesloten derde' heeft een verlammend effect op veel wetenschappelijke en maatschappelijke discussies. Het achterliggende denkpatroon laat zich volgens cultureel antropoloog Peter Kloos (1987) als volgt karakteriseren: 1) er zijn verschillen; 2) verschillen zijn contrasten; 3) contrasten zijn tegenstellingen; 4) van tegengestelde verschijnselen is er maar één waar; 5) bij tegenstellingen moet derhalve gekozen worden, waarbij aanvaarding van de ene kant verwerping van de andere inhoudt.

Door dit denkpatroon is er een hele reeks van tweedelingen ontstaan die stuk voor stuk aanleiding hebben gegeven tot debatten die allemaal uitzichtloos zijn gebleken omdat de mislukking ervan al was ingebouwd. Onder het mom van 'hoor en wederhoor' koesteren de media een 'pro en contra-model' dat elk twistgesprek in een discussie onder doven laat ontaarden. Roept iemand dat we morgen (en het is nu al 'vijf voor twaalf) kopje onder gaan dan gaat men naarstig op zoek naar een scepticus of contrarian die globale opwarming afdoet als een fabeltje van de 'broeikasmaffia'.

Een voorbeeld van zo'n non-debat is het telkens terugkerend gepalaver over de grote grazers rond de Oostvaardersplassen. Ze werden hier ooit geïntroduceerd en ingezet als motoren van de natuurlijke dynamiek, een functie die zij beter kunnen vervullen naarmate ze zich natuurlijker gedragen. Daartoe moeten ze aan een langdurig proces van 'dedomesticatie' worden onderworpen, via een terughoudend beleid inzake bijvoederen en veterinaire bijstand. En het is precies dit 'verwilderings' proces dat regelmatig publieke weerstand oproept en zo ongeveer jaarlijks tot politieke commotie leidt. ${ }^{14}$

De achterliggende vraag betreft de status van deze dieren. Dierenbeschermers en dierethici beschouwen grote grazers als gedomesticeerde dieren, waarbij de individuele zorgplicht onverkort van kracht behoort te zijn. Natuurbeschermers en eco-ethici menen daarentegen dat de uitgezette runderen en paarden in niets verschillen van de al lang in het wild levende herten en reeën, waarvoor nu juist een afblijfplicht geldt. 
Ziedaar de patstelling: de dieren zijn ofwel gehouden en gedomesticeerd, ofwel wild. Een derde mogelijkheid wordt niet erkend, terwijl daarin nu juist de oplossing van het conflict schuilt. De dieren zijn in feite noch volledig gedomesticeerd, noch volledig wild, maar doorlopen een langdurig proces van dedomesticatie, waarbij zij zich stapje voor stapje van een door en door culturele naar een meer en meer natuurlijke context bewegen. In het experiment van dedomesticatie zijn beide strijdende partijen tot elkaar veroordeeld en zullen zij elkaars recht van spreken over en weer volmondig moeten erkennen. Om dat te bereiken moeten beide partijen leren om datgene te ontwikkelen wat Donald Schön en Martin Rein ooit als 'dubbele visie' hebben aangeduid: 'het vermogen om binnen een bepaald kader te werken en tegelijkertijd het bewustzijn te cultiveren dat er ook andere kaders bestaan'. ${ }^{15}$ We moeten, om Peter Kloos te citeren, leren 'de werkelijkheid te bezien met die bijzondere vorm van scheelheid die ons in staat stelt van twee kanten naar hetzelfde verschijnsel te kijken'. ${ }^{16}$ Pas dan kan er een goede balans gevonden worden tussen de zorg voor de gezondheid en het welzijn van individuele dieren en het respect voor hun (potentiële) wildheid, vrijheid en autonomie - een balans die uiteraard verschuift naarmate de dieren op eigen poten leren staan. ${ }^{17}$

\section{Reframing en de notie van duurzaamheid}

Een andere belangrijke methode om conflicten hanteerbaar te maken is reframing. Om hardnekkige controverses te kunnen begrijpen moeten we volgens Donald Schön niet zozeer kijken naar de manier waarop problemen worden opgelost, maar veeleer naar de manier waarop ze worden gedefinieerd. Slepende beleidscontroverses hebben maar al te vaak betrekking op conflicterende frames of denkkaders en kunnen dan ook meestal het best worden opgelost door reframing, dat wil zeggen door een herstructurering of reconstructie van kaders die een nieuwe probleemdefinitie mogelijk maken, een definitie 'waarin we conflicterende kaders proberen te integreren door elementen en verbanden uit bestaande verhalen op te nemen zonder de interne coherentie of de voor actie vereiste graad van eenvoud op te offeren'. ${ }^{18}$ Een geslaagd voorbeeld van reframing levert de notie van duurzaamheid in het klimaatdebat.

Ook in de controverses over het klimaatbeleid spelen verschillen in probleemperceptie een sleutelrol. Ik beperk me hier tot wat wellicht als het meest fundamentele verschil aangemerkt kan worden. Terwijl het geïndustrialiseerde Noorden er overwegend een 'ecologische visie' op nahoudt, waarbij klimaatverandering in wezen als misdaad tegen de natuur beschouwd wordt, zien de ontwikkelingslanden klimaatverandering primair als een welzijnsprobleem, waarbij niet de natuur maar de mens het voornaamste slachtoffer is.

Vanuit het perspectief van het geïndustrialiseerde Noorden ligt de nadruk op de impact van klimaatverandering op natuurlijke systemen: het inkrimpen van gletsjers, het ontdooien van de permafrost, het bleken van koraal, het uitsterven van soorten, het verlies van biodiversiteit, et cetera. Vanuit het perspectief van de zuidelijke ontwikkelingslanden ligt daarentegen het accent op de effecten van klimaatverandering 
op humane systemen, effecten die vooral in de arme regionen gevoeld zullen worden: vermindering van de oogst in de meeste tropische en subtropische streken met alle gevolgen van dien voor de voedselvoorziening en de werkgelegenheid; gedwongen verhuizing van mensen uit kleine eilandstaten en laaggelegen kustzones; blootstelling van miljoenen mensen aan nieuwe gezondheidsrisico's, met name malaria, cholera en dysenterie. De verwachte verdeling van de economische effecten van klimaatverandering is volgens het Intergovernmental Panel on Climate Change (IPCC) zodanig 'dat ze de ongelijkheid in welzijn tussen ontwikkelde landen en ontwikkelingslanden zou vergroten'.

Met deze verschillen in probleemperceptie tussen rijke en arme landen corresponderen ruwweg twee strategieën om aan klimaatverandering het hoofd te bieden: mitigatie en adaptatie. Mitigatie is gericht op een reductie van de emissie van broeikasgassen. Adaptatie is gericht op aanpassing aan de effecten van klimaatverandering, bijvoorbeeld door dijkverhoging of de ontwikkeling van gewassen die resistent zijn tegen droogte. Terwijl mitigatie de oorzaken van klimaatverandering aanpakt, richt adaptatie zich dus op de gevolgen.

Vanwege hun grotere kwetsbaarheid is adaptatie van vitaal belang voor de ontwikkelingslanden. Tegelijkertijd missen zij de menselijke, financiële en natuurlijke hulpbronnen en de institutionele en technologische mogelijkheden voor succesvolle adaptatie. Dat is temeer wrang omdat deze arme landen met een onevenredig deel van de lasten van klimaatverandering opgezadeld worden terwijl zij veel minder (causaal) verantwoordelijk zijn voor klimaatverandering dan de rijke landen.

Niettemin had mitigatie in het globale klimaatbeleid tot voor kort voorrang boven adaptatie. Als een van de redenen hiervoor noemt het IPCC dat adaptatie met een houding van fatalisme of berusting in verband gebracht wordt. 'Door te veel nadruk op adaptatiestrategieën te leggen zou men de indruk kunnen wekken dat mitigatie-inspanningen weinig effect hebben, dat klimaatverandering onvermijdelijk is, en/of dat mitigatiemaatregelen onnodig zijn.' Aan de andere kant ervaren ontwikkelingslanden deze prioriteitstelling als vorm van neokolonialisme - zij worden voortdurend opgeroepen, vooral door de Verenigde Staten, de grootste vervuiler, om zich te committeren aan afspraken over emissiereducties terwijl ze bezig zijn met een inhaalslag ten opzichte van de industrielanden die hun huidige hoge welvaartpeil te danken hebben aan een ongebreidelde $\mathrm{CO}_{2}$-uitstoot in verleden én heden.

De kloof tussen beide visies is recent overbrugd door de reframing van het probleem van klimaatverandering in het brede kader van duurzame ontwikkeling. Hoewel het duurzaamheidsconcept al vanaf het midden van de jaren tachtig beschikbaar was, heeft het lang geduurd voordat dit concept in de klimaatdiscussie werd opgenomen.

Krisis 2007 I 2 Zoals het IPCC in 2001 heeft opgemerkt, hebben het discours over klimaatverandering en dat over duurzame ontwikkeling tot voor kort min of meer gescheiden wegen gevolgd.

Het onderzoek over duurzame ontwikkeling heeft er in het algemeen geen rekening mee gehouden hoe de gevolgen van klimaatverandering van invloed kunnen zijn 
op de inspanningen om te komen tot meer duurzame samenlevingen. Omgekeerd ontbreken methodologische en substantiële argumenten van duurzame ontwikkeling nog steeds in het vertoog over klimaatverandering. ${ }^{19}$

Het concept van duurzame ontwikkeling functioneert als een soort brugconcept omdat het twee koppelingen tot stand brengt: een koppeling tussen ecologie en economie, en een koppeling tussen intergenerationele rechtvaardigheid en intragenerationele rechtvaardigheid, zoals naar voren komt in de bekende definitie uit het Brundtland-rapport Our common future uit 1987: 'Sustainable development is development that meets the needs of the present generation without compromising the ability of future generations to meet their own needs. ${ }^{20}$ Economische groei hoeft niet onvermijdelijk gepaard te gaan met ecologisch verval, terwijl onze aandacht voor de behoeften van toekomstige generaties niet ten koste mag gaan van de aandacht voor de behoeften van de huidige generaties. Gegeven deze koppelingen, steunt het concept van duurzame ontwikkeling op drie pijlers: economische voorspoed (ontwikkeling), ecologische integriteit (duurzaamheid) en sociale rechtvaardigheid (tussen en binnen generaties).

Integratie van het vertoog over klimaatverandering in het kader van duurzame ontwikkeling heeft grote voordelen omdat dit kader allerlei synergieën en trade-offs tussen uiteenlopende doelen mogelijk maakt: milieubescherming, economische groei, sociale gelijkheid, armoedebestrijding enzovoort. Het concept van duurzame ontwikkeling dankt dit vermogen diverse en vaak ook divergerende perspectieven en doelen te verenigen aan haar flexibiliteit en openheid voor een grote veelheid en verscheidenheid aan interpretatiemogelijkheden. Op dit punt ontpopt dit concept zich als een echt 'grensobject'. Wat dat inhoudt wil ik uitleggen aan de hand van mijn tweede voorbeeld, waarin het duurzaamheidsconcept een belangrijke rol speelt.

\section{'Grensobjecten' en het clean development mechanism}

De derde pragmatische strategie om conflicten beheersbaar te maken is in het pragmatisch geïnspireerde wetenschaps- en technologieonderzoek onder de noemer van boundary work tot ontwikkeling gekomen. Deze term werd in 1981 gelanceerd door Steven Woolgar die twee jaar voordien samen met Bruno Latour het baanbrekende boek Laboratory life. The construction of scientific facts publiceerde. Het begrip werd door Thomas Gieryn verder ontwikkeld en uitgewerkt. Gieryns onderzoek is gericht op de strategieën die mensen hanteren om hun activiteiten te onderscheiden van nietwetenschappelijke activiteiten teneinde hun cognitieve autoriteit ten aanzien van bepaalde thema's of terreinen te vestigen. De grenzen der wetenschap zijn volgens Gieryn eerder vloeibaar dan vast - ze zijn 'ambigu, elastisch, historisch veranderlijk, contextueel variabel, intern inconsistent en soms omstreden'. ${ }^{21}$

In Gieryns werk ligt alle nadruk op differentie en demarcatie, op de retorische methoden van uitsluiting en insluiting waarmee de ene groep (wetenschappers) zich probeert te onderscheiden van de andere (amateurs, gelovigen, kwakzalvers, charla- 
tans enzovoort). Vanuit een pragmatische inspiratie hebben Susan Leigh Star en James Griesemer het accent verlegd van competitie tussen groepen om cognitieve claims en cultureel kapitaal naar coöperatie over de scheidslijnen tussen afzonderlijke groepen en gemeenschappen heen. ${ }^{22}$

Het probleem waarvoor Star en Griesemer een oplossing zochten, is verwant aan het probleem waaraan dit artikel gewijd is: de spanning tussen de grote diversiteit van stakeholders en hun sociale werelden en de noodzaak tot communicatie en coöperatie hiertussen. Zoals zij aan de ontstaansgeschiedenis van een Amerikaans natuurhistorisch museum illustreren, wordt wetenschappelijk werk verricht door sterk uiteenlopende groepen actoren: onderzoekers van diverse disciplines, amateurs en professionals, mensen en dieren, functionarissen en visionairs. Wetenschappelijk werk is met andere woorden heterogeen, maar tegelijk vereist het samenwerking: 'om gemeenschappelijk begrip te creëren, om betrouwbaarheid over domeinen heen te garanderen en om gegevens te genereren die hun integriteit los van tijd, ruimte en lokale omstandigheden bewaren'. ${ }^{23}$

Deze 'centrale spanning' tussen de heterogeniteit van wetenschappelijk werk en de noodzaak tot samenwerking kan volgens Star en Griesemer worden opgelost door de introductie van wat zij als boundary object aanduiden. Dit zijn:

'wetenschappelijke objecten die deel uitmaken van verschillende aangrenzende sociale werelden en die voldoen aan de informatiebehoeften van elk van deze werelden. Grensobjecten zijn objecten die plastisch genoeg zijn om aangepast te kunnen worden aan lokale behoeften en aan de beperkingen van de verschillende partijen die er gebruik van maken, maar die tevens robuust genoeg zijn om een gemeenschappelijke identiteit over lokale grenzen heen te handhaven (...). Ze hebben verschillende betekenissen in verschillende sociale werelden maar hun structuur vertoont voldoende gemeenschappelijkheid om herkenbaar te zijn, een middel tot vertaling. De creatie en manipulatie van grensobjecten is een sleutelproces in de ontwikkeling en handhaving van coherentie tussen aanpalende sociale werelden'. ${ }^{24}$

Kenmerkend voor grensobjecten is dat geen enkele groep exclusieve 'vertaalrechten' of toegangsrechten kan claimen, tenminste voor zover ze afzien van het gebruik van allerlei vormen van geweld. Grensobjecten maken een gelijkberechtigde coëxistentie van conflicterende overtuigingen mogelijk zonder de noodzaak van consensus of compromis.

Geslaagde voorbeelden van grensobjecten in het klimaatdebat zijn mijns inziens de zogenaamde 'flexibele mechanismen' uit het Kyoto-protocol, die inmiddels tot de belangrijkste hoekstenen van het klimaatbeleid zijn uitgegroeid. Dit zijn marktmechanismen die industrielanden in staat stellen een deel van hun reductieverplichting via maatregelen in het buitenland te realiseren en zodoende een soepele overgang naar een $\mathrm{CO}_{2}$-armere economie mogelijk maken. Deze mechanismen zijn: internationale emissiehandel, joint implementation en het clean development mechanism. ${ }^{25}$ 
Internationale emissiehandel beperkt zich tot industrielanden met een Kyoto-verplichting. Het biedt landen die meer emissies reduceren dan waartoe ze verplicht zijn de mogelijkheid dit overschot te verkopen aan landen met een tekort. Emissiehandel leidt ertoe dat uitstoot daar wordt teruggedrongen waar dat het goedkoopst is. Bij joint implementation gaat het om samenwerking tussen industrielanden met een Kyoto-verplichting in projecten die eveneens gericht zijn op een zo kosteneffectief mogelijke emissiereductie. Het gastland, doorgaans een Oost-Europees land, waar reducties eenvoudig en goedkoop te realiseren zijn, ontvangt nieuwe technologie en knowhow, terwijl het donorland in ruil daarvoor carbon credits krijgt die het kan inzetten bij het nakomen van de eigen verplichting. Ook bij het clean development mechanism (CDM) draait het om internationale samenwerking op projectbasis, dit keer tussen industrielanden met een Kyoto-verplichting en ontwikkelingslanden zonder zo'n verplichting. $\mathrm{CDM}$-projecten dienen een tweeledig doel: ze moeten niet alleen donorlanden in staat stellen om de carbon credits te verwerven waarmee zij zo goedkoop mogelijk aan hun reductieverplichting kunnen voldoen, maar ze dienen ook tegemoet te komen aan de behoeften op het gebied van duurzame ontwikkeling van het gastland.

Deze 'flexibele mechanismen' zijn niet alleen een centenkwestie. Ze bevorderen de samenwerking tussen heel verschillende partijen - staten, bedrijven, organisaties - en tussen diverse niveaus van besluitvorming: lokaal, nationaal, regionaal en mondiaal. Op die manier kunnen ze het vertrouwen wekken dat een onmisbare voorwaarde is voor het accepteren van nieuwe en verdergaande verplichtingen, vooral van de kant van de ontwikkelingslanden.

In dit opzicht is het clean development mechanism het meest veelbelovend - het is het enige mechanisme onder het Kyoto-protocol waarin de ontwikkelingslanden betrokken zijn. Het kwam tot stand via intensieve onderhandelingen tussen Brazilië en de Verenigde Staten aan de vooravond van Kyoto en werd door waarnemers van het onderhandelingsproces tot Kyoto surprise uitgeroepen. De regering-Clinton investeerde hier zoveel energie in omdat men hoopte via CDM tegemoet te komen aan de eis van de senaat tot 'betekenisvolle participatie' van ontwikkelingslanden aan klimaatbestrijding. Een ijdele hoop naar later zou blijken, want de senaat liet zich niet over de streep trekken. CDM biedt veel voordelen en win-wingelegenheden voor de diverse groepen van stakeholders: overheidsvertegenwoordigers, projectmanagers, nonprofitorganisaties, fondsen en NGO's, lokale gemeenschappen, internationale beleidsmakers, financiële instituties, bedrijven, emissiemakelaars enzovoort.

Donorlanden ontvangen carbon credits (emissiereductiecertificaten) om zo kosteneffectief mogelijk aan hun Kyoto-verplichtingen te kunnen voldoen. Maar donorlanden zijn niet de enige investeerders. In feite dragen de meeste landen de verantwoordelijkheid voor het behalen van emissiedoelen over aan het bedrijfsleven. Ondernemingen in die landen zullen emissiereductiecertificaten willen verwerven wanneer dat naar verhouding minder kost dan maatregelen in eigen huis. Maar zij kunnen een CDMproject ook gebruiken als middel om een markt voor hun product te creëren of als manier om hun imago op te poetsen. Andere investeerders kunnen ook belang heb- 
ben bij een CDM-project. Institutionele beleggers kunnen via CDM aan portofoliodiversificatie doen of maatschappelijk verantwoord ondernemen stimuleren. Een fonds of een NGO kan in een CDM-project investeren met het doel emissiereductiecertificaten uit roulatie te nemen. De investeerder is dan niet geïnteresseerd in de commerciële mogelijkheden maar in duurzame ontwikkeling.

Ook het gastland profiteert van CDM-projecten. Het ontvangt nieuwe investeringen ter bevordering van een snellere en meer duurzame ontwikkeling, in overeenstemming met de eigen prioriteiten. Het ontvangend land kan ook profiteren van de transfer van nieuwe technologieën met een lage of helemaal geen uitstoot van broeikasgassen. Ook kunnen CDM-projecten een gunstig effect hebben op het lokale milieu, door de reductie van luchtvervuiling en waterverontreiniging, door de bescherming of het herstel van biodiversiteit enzovoort. Ze kunnen bovendien een positief effect hebben op de lokale economie en werkgelegenheid, op armoedebestrijding en op capacity building.

\section{Het wonder van de vuilnisbelt}

De vele voordelen van CDM kunnen goed geillustreerd worden aan het allereerste project dat geregistreerd werd op 18 november 2004, de dag waarop de cruciale Russische ratificatie werd aangemeld: het NovaGerar Landfill Gas to Energy Project. Doel van dit project is het opvangen van methaangas uit twee Braziliaanse vuilstortplaatsen. Dit gebeurt door overkoepeling van de vuilstortplaatsen met behulp van een ondoorlaatbare, compacte laag polyethyleen. Na opvang wordt het methaangas door generatoren in energie voor het elektriciteitsnet omgezet. Het afvalwater komt in een waterzuiveringsinstallatie terecht.

Een breed spectrum van betrokkenen zal van dit project kunnen profiteren. De investeerder - Nederland - realiseert hierdoor een deel van zijn Kyoto-verplichting op kosteneffectieve wijze. Naar verwachting leidt het project tot een emissiereductie van veertien miljoen ton $\mathrm{CO}_{2}$ over de komende eenentwintig jaar. Ten minste drie bedrijven varen wel bij dit project: EcoSecurities, een multinational op het gebied van de financiering van milieuprojecten, S.A. Paulista, een Braziliaans bedrijf dat gespecialiseerd is in afvalverwerking, en EnerG, een Britse onderneming die gespecialiseerd is in de omzetting van afvalgassen in energie.

Dit project is natuurlijk ook voordelig voor het gastland. Brazilië telt meer dan zesduizend vuilstortplaatsen waarvan driekwart onbeheerd is. Het CDM-project kan hierin verandering brengen. Het systeem van het omzetten van afvalgas in elektriciteit is een staaltje van de allernieuwste technologie op het terrein van afvalverwerking. Het Krisis 2007 | 2 project kan als demonstratieproject voor schone technologie in Brazilië en daarbuiten dienen. Bovendien kan het extra buitenlandse investeringen aantrekken, wat een positief effect heeft op de betalingsbalans en tot minder import van brandstof leidt.

Voor de lokale gemeenschap zijn er positieve effecten zowel op milieugebied als op sociaal terrein. Door het tegengaan van waterverontreiniging en luchtvervuiling en 
het terugdringen van het explosiegevaar op en rond de stortplaatsen worden de gezondheidsrisico's voor de plaatselijke bevolking sterk verminderd. Bovendien heeft het project een klein maar positief effect op de lokale werkgelegenheid vanwege de behoefte aan personeel voor beheer en exploitatie van de vuilstortplaatsen. Ten slotte zal NovaGerar tien procent van de opgewekte elektriciteit schenken aan de gemeente ten behoeve van de verlichting in scholen, ziekenhuizen en andere publieke gebouwen.

Terwijl milieuactivisten en sceptici op het wereldtoneel alle aandacht opeisen met spectaculaire beelden en pakkende slogans, gebeurt achter de coulissen regelmatig een klein wonder, want in feite wordt door zo'n CDM-project inderdaad een klein wonder verricht: het brengt partijen van diverse pluimage - die voorheen geen enkele bemoeienis met of belangstelling voor elkaar hadden - met elkaar in contact en schept hiertussen een wijdvertakt werkverband.

Natuurlijk mag er geen al te rooskleurig beeld ontstaan en kleven er ook problemen aan CDM. De gecompliceerde procedures leiden tot hoge transactiekosten. Er dreigt een ongelijke geografische verdeling van projecten en investeringsgelden ten nadele van de allerarmste landen. Ook is het mogelijk dat CDM-projecten tot een verhoogde uitstoot buiten het projectgebied leiden ('lekkage'), wat de effecten ervan tenietdoet. Meer energie-efficiëntie kan bijvoorbeeld een prijsverlagend effect hebben en zodoende de vraag naar energie opdrijven. Een ander probleem is dat van de 'laaghangende vruchten': tegen de tijd dat de ontwikkelingslanden zelf maatregelen moeten nemen, zijn de eenvoudigste en goedkoopste methoden al door de industrielanden gebruikt om aan hun verplichtingen te voldoen.

Maar deze problemen zijn te overwinnen door de ontwikkeling van betere procedures voor de vormgeving van deze projecten. De politiek zou meer interesse aan de dag moeten leggen voor dit soort nederige arbeid achter de coulissen, dat tal van overheidsinstellingen, wetenschappelijke instituten, bedrijven en maatschappelijke organisaties sinds Kyoto wereldwijd verrichten. Immers: hoe kleiner deze problemen, hoe groter de ruimte voor overleg, onderhandeling en samenwerking over de grenzen van de verschillende betrokken groepen en gemeenschappen heen. Hiermee scheppen we een klimaat van vertrouwen dat nodig is om nieuwe stappen te zetten op weg naar een effectief mondiaal klimaatbeleid. Zo'n pragmatische politiek valt verre te prefereren boven het voortgaan op de weg van de polarisatie waarop angst en alarmisme om de voorrang vechten met scepticisme en regelrecht cynisme.

Noten

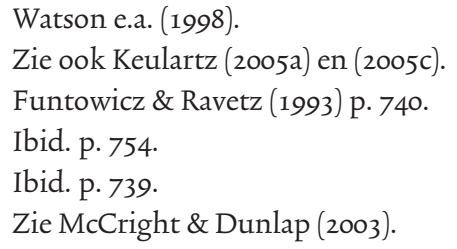

7 Al Gores eigen rampenfilm An inconvenient truth blijkt een kassucces. Deze film wordt aangekondigd als 'the most terrifying movie you will ever see’. Getoond wordt onder andere wat er met Manhattan gebeurt als het zeespiegelniveau met zeven meter stijgt. Het World Trade Centre Memorial zou onder water 
komen te staan. 'Is it possible', vraagt $\mathrm{Al}$ Gore, 'that we should prepare for other serious threats in addition to terrorism? Maybe it's time to focus on other dangers as well' (Gore 2006, p. 209).

8 Funtowicz \& Ravetz spreken in dit verband weliswaar van 'de zaden van verderf maar blijven desondanks de verwachting koesteren dat de 'democratisering' van de wetenschap door uitbreiding van de wetenschappelijke gemeenschap met leken eerder tot consensus dan conflict zal leiden. Ook Nowotny (2005) laat weten dat de 'co-evolution (of science and society) should not be taken to mean harmony', zonder daar evenwel verder op in te gaan.

9 Ook Al Gore veronderstelt dat bewustwording van het klimaatprobleem ertoe zal leiden dat de mensheid er gezamenlijk de schouders onder zet, dat de taak dit probleem op te lossen de mensen wereldwijd zal verenigen. 'The climate crisis also offers us the chance to experience what very few generations in history have had the privilege of knowing: a generational mission; the exhilaration of a compelling moral purpose; a shared and unifying cause; the thrill of being forced by circumstances to put aside the pettiness and conflict that so often stifle the restless human need for transcendence; the opportunity to rise' (Gore 2006, p. 11).

10 Ik deel de overtuiging van Michael Walzer dat we de droom van een enkele actor, de globale staat, als een waanvoorstelling moeten opgeven, en in plaats daarvan naar een 'globaal pluralisme' zouden moeten streven, 'met veel actoren, en veel arena's van activiteit en besluitvorming' (Walzer 2000, p. 10).

Krisis 2007 | 2

11 Van Kersbergen \& Van Waarden (2001).

12 In feite hebben we hier van doen met nazaten of uitlopers van het metafysisch denken dat van oudsher gepreoccupeerd is met de vraag naar de relatie van eenheid en veelheid, van deel en geheel, identiteit en differentie, individualiteit en totaliteit. Vanaf haar begin staat de westerse metafysica in het teken van de zoektocht naar de logische en ontologische oorsprong en oorzaak van al het zijnde, naar de archè die ten grondslag ligt aan de veelheid der dingen. Om de vraag naar de eenheid in de veelheid draait ook dit artikel, maar het geeft op die vraag een postmetafysisch (of postmodernistisch) antwoord. De eenheid in de veelheid der dingen wordt hier niet langer als wezensgrond of grondbeginsel opgevat, waarbij de veelheid der verschijnselen tot epifenomeen verbleekt, maar wordt pragmatisch gedacht - in termen van communicatie, coördinatie en coöperatie.

13 Deze voorbeelden van geslaagd grenswerk kunnen gemakkelijk met andere aangevuld worden. Een ander pragmatisch geïnspireerd voorbeeld is de zogenaamde common ground dialogue. In zo'n dialoog houdt men de meest basale overtuigingen buiten de discussie en gaat men op zoek naar gebieden waar overeenkomst mogelijk is. Een voorbeeld van zo'n dialoog is die tussen pro life- en pro choice-vertegenwoordigers in het abortusdebat. Gemeenschappelijk punt: de reductie van het aantal abortussen door het voorkomen van ongewenste zwangerschappen (zie Caspary 2000, pp. 48-152).

14 Zie Keulartz e.a. (1998); Klaver, Keulartz e.a. (2002).

15 Schön \& Rein (1994), p. 207.

16 Kloos (1987), p. 115.

17 De notie van 'dubbele visie' komt niet alleen overeen met wat Kloos een 'bijzondere vorm van scheelheid' noemt maar sluit eveneens goed aan bij het beeld van een facetoog (compound eye) dat Don Idhe in Philosophy of technology (1993) heeft geïntroduceerd. Door de opkomst van de snelle communicatie-, informatie- en beeldtechnologieën is de wereld in een 
mozaïek veranderd; ze kan niet meer vanuit één cultureel interpretatiekader tegemoetgetreden worden, maar vraagt in plaats daarvan om het ontwikkelen van zoiets als een compound eye. Ook kan gewezen worden op de verwantschap van de notie van 'dubbele visie' met wat in de culturele antropologie bekendstaat als comparative consciousness: het besef van de grote verscheidenheid van culturen en subculturen dat onder cultureel antropologen gemeengoed is (zie Nader 1994). Ook 'gewone mensen' bekijken de wereld onder invloed van de nieuwe media en de wereldwijde stromen van migranten, asielzoekers, toeristen en zakenlui tegenwoordig door een cultureel-antropologische bril en beoordelen hun eigen levenswijze in het licht van alle andere levens-

Literatuur

Boehmer-Christiansen, S. (1994a) Global climate protection policy. The limits of scientific advice. Part 1. Global Environmental Change 4 (2), pp. 140-159.

Boehmer-Christiansen, S. (1994b) Global climate protection policy. The limits of scientific advice. Part 2. Global Environmental Change 4 (3), pp. 185-200.

Boehmer-Christiansen, S. (2001). Disaster, failure or success? Towards a better interaction between scientists, policymakers and society groups. Annual Conference of RMNO.

Crichton, M. (2004) State of fear. Londen, HarperCollins Publishers.

Fujimura, J. (1992) Crafting science. Standardized packages, boundary objects, and 'translation'. In: A. Pickering (red.) Science as culture and practice. Chicago, University of Chicago Press, pp. 168-211.

Funtowicz, S. \& J.R. Ravetz (1993). Science for the post-normal age. Futures 25 , pp. 735-755. wijzen waarmee ze direct of indirect in contact staan.

18 Schön (1979), p. 270.

$19 \operatorname{IPCC}(2001 \mathrm{~b})$, p. 634.

20 WCED (1987), p. 43.

21 Gieryn (1983), p. 792

22 In het voetspoor van Star \& Griesemer is een hele reeks verwante concepten voorgesteld, zoals standardized packages (Fujimura 1992), boundary-ordering devices (Shackley \& Wynne 1996) en boundary organisations (Guston 2001). Een verwant concept uit wetenschapsfilosofische hoek is trading zone (Galison 1997).

23 Star \& Griesemer (1989), p. 387.

24 Ibid., p. 393.

25 Zie Keulartz (2005b).

Galison, P. (1997) Image and logic. A material culture of microphysics. Chicago, University of Chicago Press.

Caspary, W.R. (2000) Dewey on democracy. Ithaca en Londen, Cornell University Press.

Gieryn, T. (1983) Boundary-work and the demarcation of science from non-science: Strains and interests in the professional ideologies of scientists. American Sociological Review 48, pp. 781-795.

Gore, A. (2006) An inconvenient truth. The planetary emergency of global warming and what we can do about it. New York, Rodale.

Guston, D.H. (2001) Boundary organizations in environmental policy and science. An introduction. Science, Technology, \& Human values 26 (4), pp. 399-408.

Hannerz, U. (1996) Transnational connections. Cultures, people, places. Londen en New York, Routledge.

Idhe, D. (1993) Philosophy of technology. An introduction. New York, Paragon.

IPCC (Intergovernmental Panel on Climate Change) (2001a) Climate change 2001. Impacts, adaptation, and vulnerability. 
A report of Working Group II of the IPCC.

IPCC (Intergovernmental Panel on Climate Change) (2001b) Climate change 2001. Mitigation. A report of Working Group III of the IPCC.

Kersbergen, K. van \& F. van Waarden (2001) Shifts in governance. Problems of legitimacy and accountability. Den Haag, Social Science Research Council.

Keulartz, J., e.a. (1998) Op eigen poten. Ethiek rond grote grazers. KEM, Tijdschrift voor empirische filosofie 22 (3), pp. 257-289.

Keulartz, J. (2005a) Werken aan de grens. De spanning tussen diversiteit en duurzaamheid. Oratie Nijmegen, Radboud Universiteit.

Keulartz, J. (2005b) Kyoto and the ethics of flexibility. In: E. Vermeersch (red.) Reading the Kyoto Protocol. Ethical aspects of the Convention on Climate Change. Delft, Eburon Academic Publishers, pp. 117-155.

Keulartz, J. (2005c) Werken aan de grens. Een pragmatische visie op natuur en milieu. Budel, Damon.

Klaver, I., J. Keulartz e.a. (2002) Born to be wild. A pluralistic ethics concerning introduced large herbivores in the Netherlands. Environmental Ethics 24 (1), pp. 3-23.

Kloos, P. (1987) Filosofie van de antropologie. Leiden, Martinus Nijhoff.

McCright, A.M. \& R.E. Dunlap (2003)

Defeating Kyoto. The conservative movement's impact on U.S. climate change policy. Social Problems 50.

Nader, L. (1994). Comparative consciousness. In: R. Borofsky (ed.) Assessing cultural

Krisis 2007 | 2 anthropology. New York, McGraw Hill, pp. 84-96.

Nowotny, H., P. Scott \& M. Gibbons (2001) Re-thinking science. Knowledge and the public in an age of uncertainty. Cambridge UK, Polity Press.

Nowotny, H. (2005) The potential of transdisciplinarity. Interdisciplines. A website for interdisciplinary research in the humanities.
O’Neill, O. (2004) Global justice. Whose obligations. In: D. Chatterjee (red.) The ethics of assistance. Morality and the distant needy. Cambridge, Cambridge University Press, pp. 242-260.

Robertson, R. (1995) Glocalization. Timespace and homogeneity-heterogeneity. In: M. Featherstone, S. Lash \& R. Robertson (red.) Global modernities. Londen, Sage.

Schön, D.A. (1979) Generative metaphor. A perspective on problem-setting in social policy. In: A. Ortony (red.) Metaphor and thought. Cambridge, Cambridge University Press, pp. 254-284.

Schön, D. \& M. Rein (1994) Frame reflection. New York, Basic Books.

Shackley, S. \& B. Wynne (1996) Representing uncertainty in global climate change science policy. Boundary-ordering devices and authority. Science, Technology, E Human Values 21 (3), pp. 275-302.

Singer, P. (2004, tweede druk) One world. The ethics of globalization. New Haven en Londen, Yale University Press.

Star, S.L. \& J. Griesemer (1989) Institutional ecology, 'translations', and boundary objects. Amateurs and professionals in Berkeley's Museum of Vertebrate Zoology, 1907-1939. Social Studies of Science 19, pp. 387-420.

Walzer, M. (2000) International society. What is the best we can do? Published as paper number 8 on: http://www.sss.ias.edu/ home/papers.html.

Watson, R., J. Dixon, S. Hamburg, A. Janetos \& R. Moss (1998) Protecting our planet, securing our future. UNEP, U.S. NASA, The World Bank.

WCED (World Commission for Environment and Development) (1987) Our common future. Oxford, Oxford University Press.

Weston, A. (1992) Toward better problems. Philadelphia, Temple University Press.

Zweers, W. (1995) Participeren aan de natuur. Ontwerp voor een ecologisering van het wereldbeeld. Utrecht, Uitgeverij Jan van Arkel. 